\title{
Effect of membership functions and data size on the performance of ANFIS-based model for predicting path losses in the VHF and UHF bands
} \author{
Emmanuel Adetiba $* * * * * *$ \\ * Department of Electrical and Electronics Engineering, University of Ilorin, Ilorin Nigeria \\ ** Department of Physics, Sule Lamido University, Kafin Hausa, Nigeria \\ *** Department of Electrical Engineering, Ahmadu Bello University, Zaria Nigeria \\ **** Department of Telecommunication Science, University of Ilorin, Nigeria \\ ***** Department of Engineering, Manchester Metropolitan University, Manchester M1 5GD, UK \\ ******Department of Electrical and Information Engineering, Covenant University, Ota, Nigeria \\ ******Institute for Systems Sciences, Durban University of Technology, Durban, South Africa \\ *******,****Corresponding Author: oloyede.aa@unilorin.edu.ng
}

N. T. Surajudeen-Bakinde*, Nasir Faruk**, Abubakar Abdulkarim***, Abdulkarim A. Oloyede $* * * *$, Lukman A. Olawoyin $* * * *$, Segun I. Popoola $* * * * *$, Olugbenga Sowande $* * * *$ and

$\begin{array}{ll}\text { Submitted } & : 04 / 05 / 2020 \\ \text { Revised } & : 10 / 04 / 2021 \\ \text { Accepted } & : 23 / 05 / 2021\end{array}$

\begin{abstract}
This paper investigates the effect of number and shape of membership function (MF) and training data size on the performance of ANFIS model for predicting path losses in the VHF and UHF bands in built-up environments. Path loss propagation measurements were conducted in four cities of Nigeria over the cellular and broadcasting frequencies. A total of 17 broadcast transmission and cellular base stations were utilized for this study. From the results obtained, it can be concluded for the broadcasting bands that the generalized bell MF shows better performance with an average RMSE of $3.00 \mathrm{~dB}$ across all the routes, followed by gaussian, $\mathrm{Pi}$, trapezoid, and triangular MFs in that order with average RMSE values of $3.09 \mathrm{~dB}, 3.11 \mathrm{~dB}, 3.16 \mathrm{~dB}$, and $3.23 \mathrm{~dB}$, respectively. For the cellular systems, triangular MF outperformed other MFs with the lowest average RMSE. The generalized bell MF was found to be suited for WCDMA band, while triangular MF is most suited for GSM band. Furthermore, it can also be concluded that the higher the number of membership functions, the lower the RMSE, whereas a decrease in the data size leads to a reduction in the RMSE values. The findings of this study would help researchers and network planners make a more informed decision on choosing appropriate system parameters when modeling ANFIS models for path loss prediction.
\end{abstract}

Keywords: ANFIS; Membership function; Path loss; VHF; UHF. 


\section{INTRODUCTION}

More flexible ways of communication at much reduced costs are being provided by wireless technology. Increased efficiency, greater flexibility, availability, and mobility for users, all at cost-effective installation and maintenance, are some of the advantages of wireless technology (when compared to wired) that made it attractive and highly sought for. To ensure that the increasing subscribers are well taken care of in terms of signal coverage and good quality of service, the propagation path must be predicted in the planning and designing of wireless systems. This is because the degradation of signal strength as signal travels from the source to the destination is inevitable. There are different propagation models used in this prediction, but the most appropriate one for a particular environment or a specific communication system is difficult to ascertain.

The challenge of getting the most appropriate and efficient propagation model at reduced complexity led to the introduction of artificial intelligence (AI) and heuristic algorithms to predict path loss of wireless communication systems in the very high frequency (VHF) and ultra-high frequency (UHF) bands. Researchers have worked using different AI techniques in predicting path losses as found in (Eichie, Oyedum, \& A., 2017); (Sotirious, Sotirious, Konstantinos, Katherine, \& John, 2013); (Ozdemir, K., \& Gulsen, 2014); (Tamma, Rabbie, \& Mustafa, 2015). Equally, the use of heuristic algorithms in the prediction of path losses in urban macro-cellular environment is increasing (Dela \& Caluyo, 2013); (Salman, et al., 2018); (Surajudeen-Bakinde, et al., 2018). However, few works are found on the investigation of the suitability of the Adaptive Network based Fuzzy Inference System (ANFIS) technique for path loss prediction in the VHF and UHF bands. More so, it is pertinent to test the efficacy of the ANFIS method because of the peculiarity of the terrain environment and the wide deployment of wireless systems operating on both bands.

It was concluded in another research work of these authors in (Surajudeen-Bakinde, et al., 2018) that the ANFIS model can deliver efficient path loss predictions required for radio coverage evaluation and interference feasibility studies in multitransmitter radio network planning in the VHF bands. In another previous work by (Faruk, et al., 2019), it was reported that the ANFIS method generally performed better with least RMSE and ME across all the transmitters for UHF bands in comparison with the empirical models considered. It was also shown in the paper that, within the UHF bands considered, the ANFIS method was generally more efficient than the empirical path loss prediction models considering RMSE as the performance criterion.

Despite these efforts, the effects of the system parameters such as the number and shape of membership functions and the data density on the performance of distance based ANFIS model for path loss predictions have not been truly investigated. These parameters have been found to influence most of the designed ANFIS-based model deployed for different applications. This paper therefore investigates the effect of number and shape of membership functions (MF), and data density on the performance of ANFIS model for predicting path losses in the VHF and UHF bands in built-up environments. This would be done by examining the path loss propagation measurements in four cities of Nigeria over the cellular and broadcasting frequencies. A total of 17 broadcast transmission and cellular base stations would be utilized for this study. Data to be collected are the received signal strength (RSS), distance, frequencies scrambling codes, longitude, latitude, and elevation

\section{REVIEW OF RELATED WORKS}

Researchers across the globe have done lots of work using the different propagation models available. A few of these related works are reviewed. The practical error bounds of empirical and semiempirical path loss propagation models have been widely tested in different set of environments and across various routes and frequencies (Jimoh, et al., 2015); (Faruk, Adediran, \& Ayeni, On the study of empirical path loss models for accurate prediction of TV signal for secondary users, 2013) ; (Faruk, et al., 2016); (Onidare, et al., 28-39); (Popoola, et al., 2017), common 
findings revealed inconsistent performance. The works in (Oloyede, Faruk, \& Bello, 2016) reported that the distribution of the prediction errors of the empirical models followed the terrain profile of the routes and that the gaussian normal distribution (GND) is a splendid prediction errors approximation for both bands. In the same vein, AI techniques and heuristics algorithms such as the artificial neural network (ANN), fuzzy logic, and the ANFIS methods have been applied in different terrains and on different bands considering varying communication systems (Tamma, Rabbie, \& Mustafa, 2015); (Tamma, Rabbie, \& Mustafa, 2015); (JongKoo, 2007); (Dalkilic, Kula, \& Hanci, Path Loss Prediction by Robust Regression Methods, 2014); (Vishal \& Sharma, 2009); (Aymen \& Mohammed, 2012); (Jimoh, et al., 2015); (Dalkilic, Hanci, \& Apadydin, Fuzzy adaptive neural network approach to path loss prediction in urban areas at GSM-900 band, , 2010); (Ozdemir, K., \& Gulsen, 2014) ; (Popoola, et al., 2019); (Popoola, Jefia, Atayero, Kingsley, \& Nasir Faruk, 2019); (Popoola, et al., 2017); (Popoola, et al., 2018); (DasMahapatra, 2015). The results from these studies revealed that the ANN method was generally found to be more efficient and mostly achieved a lower RMSE and was better in performance than the theoretical and the empirical propagation models in their prediction accuracies, complexity, and computation time. In some exceptional scenarios, the ANFIS models were found to perform better than the ANN models. In another study (Faruk, et al., 2019), the ANFIS model was concluded to be more efficient and useful than the other models considered. Similar findings were presented by (Faruk, Adediran, \& Ayeni, On the study of empirical path loss models for accurate prediction of TV signal for secondary users, 2013); (Faruk, et al., 2019), where the heuristic, geospatial, and empirical models were used to predict path losses in the UHF and VHF bands. The performance of the different methods varied with the performance metrics used. It was found that, in the VHF bands, across cities, the heuristic methods (i.e., ANFIS and ANN) provided the lowest mean prediction error. In all the scenarios presented by the works, the AI methods outperformed the empirical and theoretical models.

Considerable efforts have been devoted to investigating the effects of the system parameters such as the number and shape of membership functions (MF) on the performance ANFIS models. In the work by (Surajudeen-Bakinde et al, 2018a) (Surajudeen-Bakinde, et al., 2018), the impact of MF on the training RMSE for the model was explored. The impact of membership types and epoch size on RMSE was presented, which showed how the membership type provides stability to attain fast convergence with a minimum of epochs. It was observed that Pi has the lowest RMSE for all the membership functions for all the epochs and the three different broadcast stations considered. In another related work by same authors, the same five types of membership functions were considered but for only one broadcast station and one route. It was concluded that the generalized bell membership function produced the lowest RMSE among the five different membership functions considered for one route (Surajudeen-Bakinde, et al., 2018).

In Table 1, we provide the taxonomy of related works done across the globe with different MFs. The table provides the areas of applications, the membership functions used, performance metrics employed, and the findings obtained from the work. Gaussian MF was implemented in the investigation into the effect of MF on the performance of ANFIS for solving classification problem by (Talpur, MohdSalleh, \& Hussain, 2017) . In another work, Pi MF was used, where the focus was mainly on the basic framework of the fuzzy neural network controller, described in the context of RSSI, with application to different wireless link quality indicators. The simulation results show that the proposed control scheme effectively guides the whole multirobot system to converge to the desired communication coverage as the RSSI in general converges towards the desired RSSI range of $0.2-0.24$ (Zhong \& Zhou, 2012). In (Phaiboon, Phokharatkul, \& Kittithamavongs, Muti-Layer Fuzzy Logic Sets for Mobile Path Loss in Forests., 2006), the triangular MF was made used of in the prediction of path loss using MLFL in forests, and the percentage error as the performance metric was lower for all the three path loss exponents considered for both the high density and low density forests. The percentage errors for the high density forest for both MLFL and conventional are presented in Table 1.

Seven different MFs were used in the prediction of enterprise resource planning (ERP) system. Both training and testing data predicted different outputs for all the MFs considered. Triangular MF (TRIMF) predicted the best 
ERP user satisfaction value out of the MFs that were considered (Gupta, Sharma, \& Sharma, 2014). In another study by the same authors in (Gupta, Verma, \& Mehlawat, 2011), triangular MF was equally applied in the prediction of path loss in fringe areas using Fuzzy Logic. The fuzzy path loss slope increases from 2 to 4 as the membership function signal level decreases from very large to nearly zero, respectively. (Dela \& Caluyo, 2013) applied Gaussian and exponential MFs for path loss prediction in specific urban areas using ANFIS, and the relative error obtained was 0.2303. In a bid to search for most suitable MF, in Table 1, we saw how researchers (Gupta, Sharma, \& Sharma, 2014); (Gupta S. , 2015); (Gupta, Verma, \& Mehlawat, 2011) have tested from 2 to 6 different MFs. The domains of applications were, however, in the compressive strength of concrete, optimization techniques, antenna control, inductor motor drive, and AC voltage controller. Interestingly, among all the contending MFs and across all the studies, the triangular MF gives the best performance.

Table 1. Taxonomy of Related Papers.

\begin{tabular}{|c|c|c|c|c|c|}
\hline $\begin{array}{l}\mathbf{S} / \\
\mathbf{N}\end{array}$ & Publication & Domain & $\begin{array}{c}\text { Membership } \\
\text { Function }\end{array}$ & $\begin{array}{l}\text { Performance } \\
\text { Metric Used }\end{array}$ & Outcomes \\
\hline 1 & $\begin{array}{l}\text { (Hosseinzadeh, } \\
\text { Curtis, \& } \\
\text { Wixted, 2019) }\end{array}$ & $\begin{array}{l}\text { Estimation of } \\
\text { signal } \\
\text { propagation }\end{array}$ & Clustering & $\begin{array}{l}\text { Bench marked } \\
\text { with extensive } \\
\text { practical data, }\end{array}$ & $\begin{array}{l}\text { The developed model has } \\
\text { excellent generalization } \\
\text { capability }\end{array}$ \\
\hline 3 & $\begin{array}{l}\text { (Dalkilic, Kula, } \\
\& \text { Hanci, Path } \\
\text { Loss Prediction } \\
\text { by Robust } \\
\text { Regression } \\
\text { Methods, 2014) }\end{array}$ & $\begin{array}{l}\text { Regression } \\
\text { measurements }\end{array}$ & $\begin{array}{l}\text { Regression } \\
\text { methods }\end{array}$ & MSE & $\begin{array}{l}\text { Robust methods don't } \\
\text { necessitate the equality } \\
\text { of the heights and } \\
\text { distance of buildings, }\end{array}$ \\
\hline 4 & $\begin{array}{l}\text { (Erik, Hans- } \\
\text { Jurgen, \& } \\
\text { Hajime, 2013) }\end{array}$ & $\begin{array}{l}\text { ANN-based } \\
\text { Path-Loss } \\
\text { Prediction for } \\
\text { CDMA }\end{array}$ & $\begin{array}{l}\text { Levenberg- } \\
\text { Marquardt } \\
\text { algorithm }\end{array}$ & $\begin{array}{l}\text { correlation } \\
\text { factor, and the } \\
\text { AHRE metric }\end{array}$ & $\begin{array}{l}\text { maximum error: } 22 \mathrm{~dB} \\
\text { mean error: } 0 \mathrm{~dB} \\
\text { standard deviation: } 7 \mathrm{~dB} \text {, } \\
\text { correlation coefficient: } \\
0.75 \text {, and AHRE: } 12 \% .\end{array}$ \\
\hline 5 & $\begin{array}{l}\text { (Surajudeen- } \\
\text { Bakinde, et al., } \\
\text { 2018) }\end{array}$ & $\begin{array}{l}\text { Path loss } \\
\text { Prediction in } \\
\text { the VHF band }\end{array}$ & $\begin{array}{l}\text { Generalized } \\
\text { bell } \\
\text { Triangular } \\
\text { Trapezoidal } \\
\text { Gaussian } \\
\text { Pi }\end{array}$ & $\begin{array}{l}\text { RMSE and } \\
\text { ME }\end{array}$ & $\begin{array}{l}\text { Pi has the lowest RMSE } \\
\text { and ME of } 5.2 \mathrm{~dB} \text { and - } \\
0.000003888 \mathrm{~dB}\end{array}$ \\
\hline 6 & $\begin{array}{l}\text { (Surajudeen- } \\
\text { Bakinde, et al., } \\
\text { 2018) }\end{array}$ & $\begin{array}{l}\text { Path loss } \\
\text { Prediction }\end{array}$ & $\begin{array}{l}\text { Generalized } \\
\text { bell } \\
\text { Triangular } \\
\text { Trapezoidal } \\
\text { Gaussian } \\
\mathrm{Pi}\end{array}$ & $\begin{array}{l}\text { RMSE, SDE, } \\
\text { and } \\
\text { correlation } \\
\text { coefficient (R) } \\
\text { values }\end{array}$ & $\begin{array}{l}\text { Generalized bell has the } \\
\text { lowest RMSE, SDE and } \\
\mathrm{R} \text { as } 4.45 \mathrm{~dB}, 4.47 \mathrm{~dB} \text {, } \\
\text { and } 0.92 \text { respectively }\end{array}$ \\
\hline
\end{tabular}




\begin{tabular}{|c|c|c|c|c|c|}
\hline 7 & $\begin{array}{l}\text { (Faruk, et al., } \\
\text { 2019) }\end{array}$ & $\begin{array}{l}\text { AI in path loss } \\
\text { prediction }\end{array}$ & $\begin{array}{l}\text { Generalized } \\
\text { Bell }\end{array}$ & $\begin{array}{l}\text { RMSE, SC- } \\
\text { RMSE, ME, } \\
\text { SDE }\end{array}$ & $\begin{array}{l}\text { The performance metrics } \\
\text { for ANFIS were of better } \\
\text { values in comparison to } \\
\text { four empirical models }\end{array}$ \\
\hline 8 & $\begin{array}{l}\text { (Faruk, et al., } \\
\text { 2019) }\end{array}$ & $\begin{array}{l}\text { Path Loss } \\
\text { Prediction in } \\
\text { VHF and UHF } \\
\text { bands }\end{array}$ & $\begin{array}{l}\text { Generalized } \\
\text { bell-shaped }\end{array}$ & MPE, RMSE & $\begin{array}{l}\text { RMSE values for } \\
\text { heuristic methods were } \\
\text { the least while MPE was } \\
\text { lowest for COST } 231 \text { and } \\
\text { vary across other } \\
\text { methods }\end{array}$ \\
\hline 9 & $\begin{array}{l}\text { (Talpur, } \\
\text { MohdSalleh, \& } \\
\text { Hussain, 2017) }\end{array}$ & $\begin{array}{l}\text { Classification } \\
\text { Problems }\end{array}$ & $\begin{array}{l}\text { Trapezoidal, } \\
\text { triangular, } \\
\text { Gaussian and } \\
\text { Generalized } \\
\text { Bell }\end{array}$ & RMSE & $\begin{array}{l}\text { Gaussian MF performed } \\
\text { best with least RMSE } \\
0.1420\end{array}$ \\
\hline 10 & $\begin{array}{l}\text { (Gupta, Verma, } \\
\text { \& Mehlawat, } \\
\text { 2011) }\end{array}$ & $\begin{array}{l}\text { Prediction of } \\
\text { enterprise } \\
\text { resource } \\
\text { planning user } \\
\text { satisfaction }\end{array}$ & $\begin{array}{l}\text { Triangular, } \\
\text { Trapezoidal, } \\
\text { Gaussian, } \\
\text { gauss2mf, } \\
\text { Pinmf, dsigmf } \\
\text { and Psigmf }\end{array}$ & $\begin{array}{l}\text { Constant and } \\
\text { linear }\end{array}$ & $\begin{array}{l}\text { Triangular MF gave the } \\
\text { best prediction }\end{array}$ \\
\hline 11 & $\begin{array}{l}\text { (Phaiboon, } \\
\text { Phokharatkul, \& } \\
\text { Kittithamavongs } \\
\text {, Muti-Layer } \\
\text { Fuzzy Logic } \\
\text { Sets for Mobile } \\
\text { Path Loss in } \\
\text { Forests, 2006) }\end{array}$ & $\begin{array}{l}\text { Path Loss } \\
\text { prediction in } \\
\text { Forests using } \\
\text { multi layer } \\
\text { fuzzy logic }\end{array}$ & Triangular & $\begin{array}{l}\text { Percentage } \\
\text { error }\end{array}$ & $\begin{array}{l}\text { Percentage error for the } \\
\text { three path loss exponents } \\
\text { were lower in MLFL in } \\
\text { both high density and } \\
\text { low density areas }\end{array}$ \\
\hline 12 & $\begin{array}{l}\text { (Gupta, Sharma, } \\
\text { \& Sharma, } \\
\text { 2014) }\end{array}$ & $\begin{array}{l}\text { Path Loss } \\
\text { Prediction in } \\
\text { Fringe Areas }\end{array}$ & Triangular & $\begin{array}{l}\text { Linear } \\
\text { regression }\end{array}$ & $\begin{array}{l}\text { Optimum results were } \\
\text { obtained. }\end{array}$ \\
\hline 13 & $\begin{array}{l}\text { (Zhong \& Zhou, } \\
\text { 2012) }\end{array}$ & $\begin{array}{l}\text { Deployment } \\
\text { of mobile } \\
\text { robots using } \\
\text { FNN }\end{array}$ & $\mathrm{Pi}$ & RSSI & $\begin{array}{l}\text { RSSI converges towards } \\
0.2 \text {, } \\
0.24 \text { as the MRS } \\
\text { approaches a } \\
\text { communication coverage }\end{array}$ \\
\hline
\end{tabular}




\begin{tabular}{|c|c|c|c|c|c|}
\hline 14 & $\begin{array}{l}\text { Erbay Dalkilic et } \\
\text { al (2010) }\end{array}$ & $\begin{array}{l}\text { Path loss } \\
\text { prediction in } \\
\text { specific urban } \\
\text { areas }\end{array}$ & $\begin{array}{l}\text { Gaussian and } \\
\text { Exponential }\end{array}$ & MSE & $\begin{array}{l}\text { The ANFIS model gave } \\
\text { approximately } 15 \% \\
\text { better result than } \\
\text { Bertoni-Walfisch model }\end{array}$ \\
\hline 15 & $\begin{array}{l}\text { (Gupta S. } \\
2015)\end{array}$ & $\begin{array}{l}\text { compressive } \\
\text { strength of } \\
\text { concrete }\end{array}$ & triangular & RMSE, MAE & $\begin{array}{l}\text { RMSE of } 1.008 \text { and } \\
\text { MAE of } 5.76\end{array}$ \\
\hline 17 & $\begin{array}{l}\text { (Ali, Ali, \& } \\
\text { Sumait, 2015) }\end{array}$ & $\begin{array}{l}\text { Antenna } \\
\text { Control }\end{array}$ & $\begin{array}{l}\text { Triangular, } \\
\text { trapezoidal } \\
\text { Gaussian }\end{array}$ & $\begin{array}{l}\text { System } \\
\text { Response time }\end{array}$ & $\begin{array}{l}\text { triangular MF shows } \\
\text { better performance }\end{array}$ \\
\hline 18 & $\begin{array}{l}\text { (Zhao \& Bose, } \\
\text { 2002) }\end{array}$ & $\begin{array}{l}\text { Inductor } \\
\text { Motor drive }\end{array}$ & $\begin{array}{l}\text { Triangular, } \\
\text { trapezoidal, } \\
\text { Gaussian, bell, } \\
\text { sigmoidal and } \\
\text { polynomial } \\
\text { types }\end{array}$ & Rive Response & $\begin{array}{l}\text { Triangular MF give best } \\
\text { performance }\end{array}$ \\
\hline 19 & $\begin{array}{l}\text { (Monicka, } \\
\text { Sekhar, \& } \\
\text { Kumar, 2011) }\end{array}$ & $\begin{array}{l}\text { AC voltage } \\
\text { controller }\end{array}$ & $\begin{array}{l}\text { Triangular, } \\
\text { trapezoidal, } \\
\text { Gaussian, and } \\
\text { bells }\end{array}$ & $\begin{array}{l}\text { steady state } \\
\text { error }\end{array}$ & $\begin{array}{l}\text { Triangular MF give best } \\
\text { performance }\end{array}$ \\
\hline
\end{tabular}

From table 1, we acknowledged the concerted efforts by researchers in a bid to investigate the effects of the Fuzzy system parameters such as the number and shape of membership functions performance of the model. Most of the works are skewed to other domains, and extremely few works have been applied to distance based ANFIS model for path loss predictions. Also, most of the works only considered the shape of the MF; the required number of each of the MF type needed in the model design has not been adequately addressed. Furthermore, the validity and limits of applications of these parameters need to be truly investigated in the context of distance based ANFIS path loss prediction model, particularly in build-up environments and across many bands. More so, these parameters have been found in various literatures to have influence on most of the designed ANFIS-based models deployed for different applications, as clearly and widely published, the superiority of the triangular MF against others (Gupta, Verma, \& Mehlawat, 2011); (Gupta S. , 2015); (Ali, Ali, \& Sumait, 2015); (Zhao \& Bose, 2002); (Monicka, Sekhar, \& Kumar, 2011).

\section{MEMBERSHIP FUNCTION}

Membership Function (MF), $\mu$, is the extent to which an element belongs as a member of a fuzzy set, and its variation must be between 0 and 1 . The MF in common use are the triangular, trapezoidal, generalized bell, Gaussian, and pi functions, and they are elucidated below (Roland, 2001), (JongKoo, 2007)). 


\section{A. Triangular MF}

This is a MF described by three variables $\{d, e, f\}$, where $d<e<f . d$ is the value at the starting point of the triangle, $e$ is the triangle's midpoint value, $f$ is the value at the end point of the triangle, and $x$ is the input. Eqn. (1) is used to calculate the degree of membership of a triangular MF.

$\mu_{\text {triangular }}(x)=\left\{\begin{array}{cl}0, & x<d \\ \frac{x-d}{e-d}, & d \leq x \leq e \\ \frac{f-x}{f-e}, & e \leq x \leq f \\ 0, & f \leq x\end{array}\right.$

\section{B. Trapezoidal MF}

This function is described by four variables $\{d, e, f, g\}$, where $d<e<f<g . d$ and $g$ are the starting and ending point values of the trapezoid, respectively, $e$ and $f$ are the values at the two apex points at the top of the trapezoid, respectively, and $x$ is the input. Eqn. (2) is used to calculate the degree of membership of a trapezoidal MF.

$\mu_{\text {trapezoidal }}(x)=\left\{\begin{array}{lr}0, & x \leq d \\ \frac{x-d}{e-d}, & d \leq x \leq e \\ 1, & e \leq x \leq f \\ \frac{g-x}{g-f}, & f \leq x \leq g \\ 0, & g \leq x\end{array}\right.$

\section{Generalized Bell MF}

It is usually described by three variables $\{d, e, f\}$, where $d, e$, and $f$ are the width, center, and slope of the membership function, respectively, as given in eqn. (3).

$\mu_{\text {genbell }}(x)=\frac{1}{1+\left[\left(\frac{x-f}{d}\right)^{2}\right]^{e}}$

\section{Gaussian MF}

A Gaussian MF as shown in eqn. (4) consists of two variables: $e$ - for the value at the center of the shape and $\partial$ for the width of the shape.

$\mu_{\text {gaussian }}(x)=\exp \left[-\left(\frac{x-e}{2 \partial}\right)^{2}\right]$

\section{E. Pi MF}

This is a function described by four parameters $\{d, e, f, g\}$, where $d<e<f<g$. $d$ and $g$ are the starting and ending point values of the pi shape, $e$ and $f$ are the two apex points values at the top of the shape respectively, and $x$ is the input. Eqn. (5) is used to calculate the degree of membership for this MF. 
$\mu_{p i}(x)=\left\{\begin{array}{cc}0, & x \leq d \\ 2\left(\frac{x-d}{e-d}\right)^{2}, & d<x \leq\left(\frac{d+e}{2}\right) \\ 1-2\left(\frac{x-e}{e-d}\right)^{2}, & \left(\frac{d+e}{2}\right)<x<e \\ 1, & e \leq x \leq f \\ 1-2\left(\frac{x-f}{g-f}\right)^{2}, & f<x \leq\left(\frac{f+g}{2}\right) \\ 2\left(\frac{x-g}{g-f}\right)^{2}, & \left(\frac{f+g}{2}\right)<x<g \\ 0, & x \geq g\end{array}\right.$

The shape of each of the membership functions is provided in Figure 1.

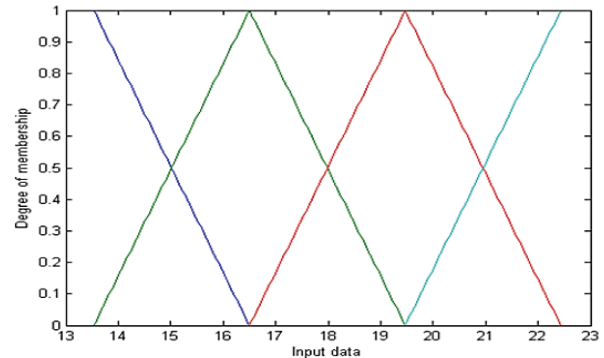

(a)

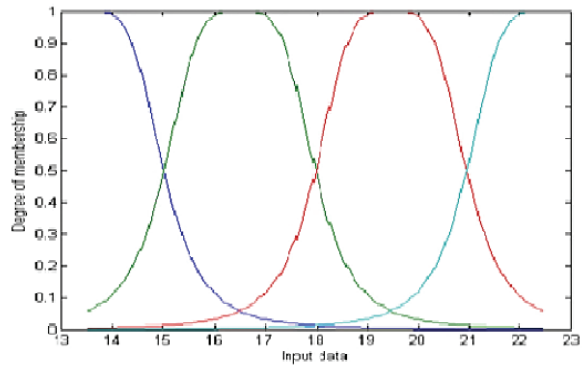

(c)

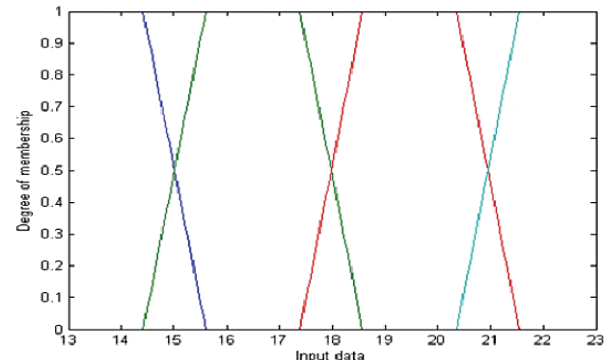

(b)

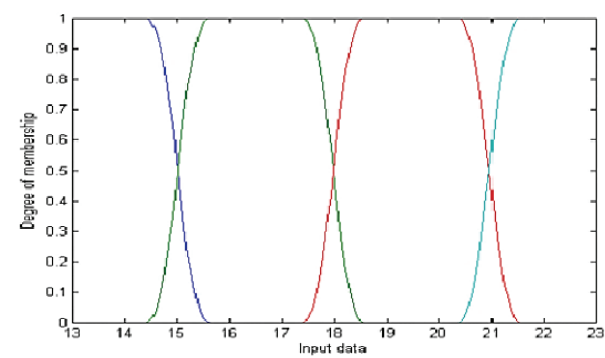

(d)

Figure 1. shape of the membership function. (a) Triangular. (b) Trapezoidal. (c) Generalized Bell. (d) Pi.

\subsection{MATERIALS AND METHODS}

\subsection{Method of Data Collection}

Propagation measurements used by the models were taken in four cities of Nigeria: Ilorin $\left(8.5^{\circ} \mathrm{N}, 4.55^{\circ} \mathrm{E}\right)$, Osogbo $\left(7.7667^{\circ} \mathrm{N}, 4.5667^{\circ} \mathrm{E}\right)$, Kano $\left(11^{\circ} 30^{\prime} \mathrm{N} 8^{\circ} 30^{\prime} \mathrm{E} 11.5^{\circ} \mathrm{N} 8.5^{\circ} \mathrm{E}\right)$, and Abuja $\left(9^{\circ} 4^{\prime} 0^{\prime \prime} \mathrm{N} 7^{\circ} 29^{\prime} 0^{\prime \prime} \mathrm{E}\right)$. The measurement campaign covered the cellular and broadcasting frequencies, which are within the VHF and UHF bands. A total of 17 transmitters were utilized, with 10 cellular base stations (i.e., 5 in the GSM and 5 in the WCDMA bands) and 7 broadcast transmitters (i.e., 3 in the VHF and 4 in the UHF bands). The data collected consisted of received signal strength (RSS), distance, frequencies scrambling codes (for 3G Node Bs), longitude, latitude, and elevation. Details of the measurement equipment and description of the broadcast transmitters and cellular bands are presented in Tables 2 and 3. 
Table 2. Description of the broadcast transmitters.

\begin{tabular}{|c|c|c|c|c|c|c|}
\hline Transmitter & Band & Frequency & Antenna & Peak power & \multicolumn{2}{|c|}{ Coordinates } \\
\hline & & $(\mathrm{MHz})$ & height (m) & $(\mathrm{kW})$ & Longitude & Latitude \\
\hline Harmony & VHF & 103.5 & 125 & 1 & $8^{\circ} 21^{\prime} 56^{\prime \prime} \mathrm{N}$ & $4^{\circ} 43^{\prime} 18^{\prime \prime} \mathrm{E}$ \\
\hline NTA, Ilorin & VHF & 203.25 & 185 & 2.4 & $8^{\circ} 25^{\prime} 55^{\prime \prime} \mathrm{N}$ & $4^{\circ} 36^{\prime} 25^{\prime \prime} \mathrm{E}$ \\
\hline Unilorin & VHF & 89.3 & 100 & 7 & $8^{\circ} 29^{\prime} 21^{\prime \prime} \mathrm{N}$ & $4^{\circ} 40^{\prime} 28^{\prime \prime} \mathrm{E}$ \\
\hline $\begin{array}{l}\text { NDTV, } \\
\text { Ibokun }\end{array}$ & UHF & 479.25 & 198 & 2.1 & $7^{\circ} 46^{\prime} 32^{\prime \prime} \mathrm{N}$ & $4^{\circ} 43^{\prime} 14^{\prime \prime} \mathrm{E}$ \\
\hline NTA, Ile Ife & UHF & 615.25 & 167 & 3.2 & $7^{\circ} 29^{\prime} 59^{\prime \prime} \mathrm{N}$ & $4^{\circ} 35^{\prime} 23^{\prime \prime} \mathrm{E}$ \\
\hline $\begin{array}{l}\text { OSBC, } \\
\text { Osogbo }\end{array}$ & UHF & 559.25 & 340 & 3.5 & $7^{\circ} 46^{\prime} 35^{\prime \prime} \mathrm{N}$ & $4^{\circ} 35^{\prime} 19^{\prime \prime} \mathrm{E}$ \\
\hline NTA, Osogbo & UHF & 695.25 & 152 & 4.1 & $7^{\circ} 44^{\prime} 01^{\prime \prime} \mathrm{N}$ & $4^{\circ} 31^{\prime} 14^{\prime \prime} \mathrm{E}$ \\
\hline
\end{tabular}

Table 3. Description of the cellular transmitters.

\begin{tabular}{|c|c|c|c|c|c|}
\hline Transmitter & Band & BTS/ARFCN & $\begin{array}{c}\text { Frequency } \\
\text { (MHz) }\end{array}$ & $\begin{array}{c}\text { Antenna height } \\
\text { (m) }\end{array}$ & $\begin{array}{c}\text { Peak power } \\
\text { (kW) }\end{array}$ \\
\hline GSM, Kano & UHF & $1 / 679$ & 1838.6 & 30 & 20 \\
\hline & UHF & $2 / 668$ & 1836.4 & 30 & 20 \\
\hline & UHF & $3 / 662$ & 1835.2 & 30 & 20 \\
\hline & UHF & $4 / 672$ & 1837.2 & 30 & 20 \\
\hline
\end{tabular}

\begin{tabular}{|c|c|c|c|c|c|}
\hline $\begin{array}{c}\text { WCDMA, } \\
\text { Abuja }\end{array}$ & Band & Node B/PSC & $\begin{array}{c}\text { Frequency } \\
\text { (MHz) }\end{array}$ & $\begin{array}{c}\text { Antenna height } \\
(\mathbf{m})\end{array}$ & $\begin{array}{c}\text { Peak power } \\
\text { (kW) }\end{array}$ \\
\hline & $\mathrm{UHF}$ & $1 / 484$ & 2112.4 & 30 & 20 \\
\hline & $\mathrm{UHF}$ & $2 / 486$ & 2112.4 & 30 & 20 \\
\hline & $\mathrm{UHF}$ & $3 / 132$ & 2112.4 & 30 & 20 \\
\hline & $\mathrm{UHF}$ & $4 / 485$ & 2112.4 & 30 & 20 \\
\hline & $\mathrm{UHF}$ & $5 / 188$ & 2112.4 & & 20 \\
\hline
\end{tabular}




\section{A. Broadcasting Frequencies Measurements}

The materials utilized for broadcasting frequency measurements comprise a handheld Agilent N9342C spectrum analyzer with an inbuilt Global Positioning System (GPS) receiver, a laptop, and a memory stick for the storage of data. For improved functioning, an external GPS receiver was connected to the analyzer and fixed to the top of the vehicle, and the spectrum analyzer itself was positioned inside the vehicle. The frequency of operation of the GPS was set in the L1 band. Table 4 provides summary of the analyzer's configuration. For each of the transmitters, three different routes were covered.

Table 4. Details of measurement equipment for the broadcast transmitters.

\begin{tabular}{|l|c|}
\hline \multicolumn{2}{|c|}{ Spectrum Analyzer N9342C Agilent, 100 Hz-7 GHz } \\
\hline Displayed Average Noise Level (DANL) & $-164 \mathrm{dBm} / \mathrm{Hz}$ \\
\hline Preamplifier & $20 \mathrm{~dB}$ \\
\hline Resolution bandwidth (RBW) & $10 \mathrm{kHz}$ \\
\hline Impedance & $50 \mathrm{Ohms}$ \\
\hline \multicolumn{2}{|c|}{ Receiver Antenna: Diamond RH799 RH 795 } \\
\hline Frequency range & $70 \mathrm{MHz}-1 \mathrm{GHz}$ \\
\hline Form & Omni directional \\
\hline Height & $1.5 \mathrm{~m}$ \\
\hline Gain & $2.51 \mathrm{dBi}$ \\
\hline
\end{tabular}

\section{B. Mobile Cellular Frequencies Measurements}

The GSM band measurements were carried out in Kano, while those for the WCDMA band were conducted in Abuja. The measurements were done on a dual band handset with special configurations, a GPS and a Probe Dongle, which were attached to a laptop equipped with Huawei Genex Probe v 6.0 drive test software. All the drive tests were conducted within the metropolis.

\subsection{ANFIS Model Development}

ANFIS was proposed in the early 1990s. ANFIS being a multilayer feedforward network with different nodes can perform specified functions on input signals as well as the parameters attributed to these nodes. There is variation in the formulas from one node to another, and the decision of each function of the nodes is dependent on the entire input-output function that is required by the adaptive network to be executed. Commonly, the popular feed-forward structure is employed in conjunction with the backpropagation training method. A disadvantage of multilayered feedforward networks, which contain many neurons per layer, is the training period required. In addition, an excessively complex ANFIS can lead to data overfitting and, as a result, problems of generalization (Erik, HansJurgen, \& Hajime, 2013). The general structure and functions of each layer of the ANFIS method are shown in Figure 2 . 


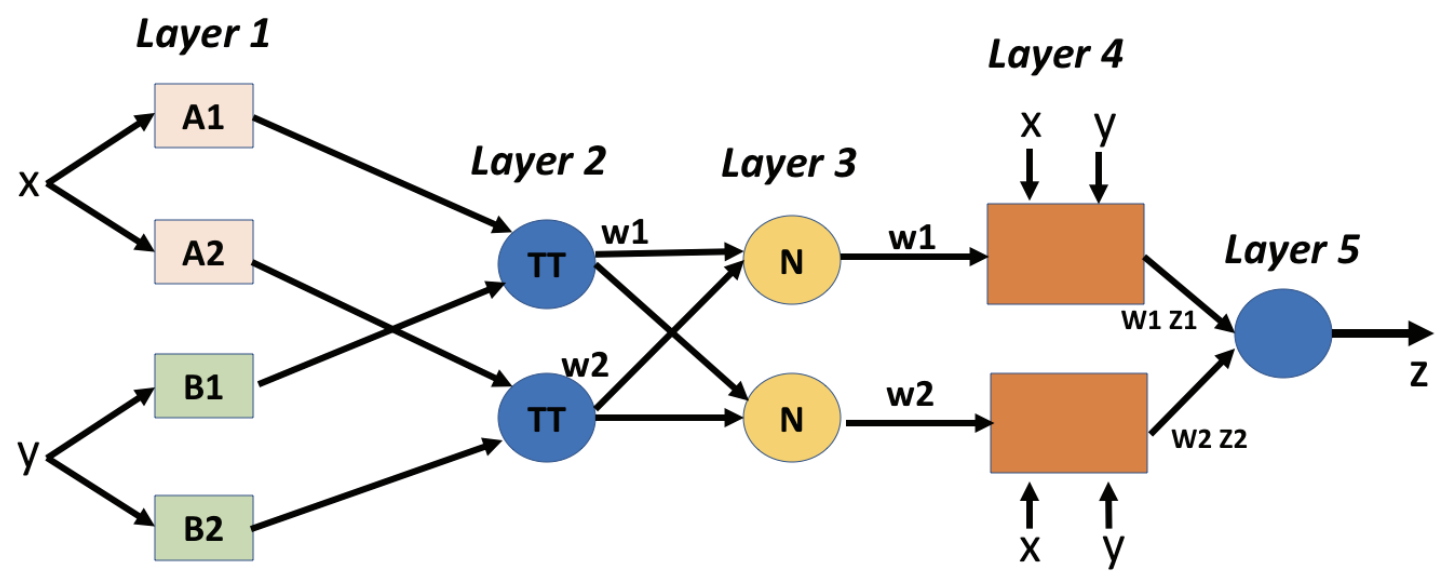

Figure 2. Two-input and two-rule ANFIS structure.

The structure consists of five layers, and the nodes in each of these layers are either stable or adaptable. The adaptable nodes are represented by the square shapes, and the stable (fixed) ones are symbolized by the circular shapes. The description of the structure is done with a first-order Sugeno, because the output is a crisp value. A Sugeno based ANFIS has a rule of the form (DasMahapatra, 2015):

If $x$ is $\mathrm{A}_{1}$ and $y$ is $\mathrm{B}_{1}$ then $f_{1}=p_{1} x+q_{1} y+r_{1}$

If $x$ is $\mathrm{A}_{2}$ and $y$ is $\mathrm{B}_{2}$ then $f_{2}=p_{2} x+q_{2} y+r_{2}$

Layer 1: A node in this layer is adaptable and is given as

$L_{i}^{1}=\mu A_{i}(x) \quad i=1,2$

The input to the $i t h$ node is $x, A_{i}$ is a changeable language relating to this node, and the $\mathrm{MF}$ of $A_{i}$ is $\mu A_{i}(x)$ which is taken normally as

$\mu A_{i}(x)=\frac{1}{1+\left[\left(\frac{x-f_{i}}{d_{i}}\right)^{2}\right]^{e_{i}}}$

$\left\{d_{i}, e_{i}, f_{i}\right\}$ is the antecedent variables set. Eqn. (9) is a representation of the generalized bell MF.

The membership function decides the mapping of each point in the input space by assigning a membership value in an interval of 0 and 1 . The input (antecedent) variables are initially generated by trial and error method. These variables are, ,therefore adjusted through the learning capability of the $\mathrm{NN}$, which enables the errors reduction to be easier and at the same time optimizing the output (consequent) variables (DasMahapatra, 2015).

Layer 2: This layer is made up of the stable nodes, which solve the firing power $w_{i}$ also known as the synaptic weight of a rule. The output of each node is the multiplication of the incoming signals given by 
$L_{i}^{2}=w_{i}=\mu A_{i}(x) \times \mu B_{i}(y), \quad i=1,2$

Layer 3: The output of each node in this layer is constant, which is given by

$L_{i}^{3}=\overline{w_{\iota}}=\frac{w_{i}}{\sum w_{i}}, \quad i=1,2$

Layer 4: The changeable output of this layer is given by

$L_{i}^{4}=\overline{w_{l}} f_{i}=\overline{w_{l}}\left(p_{i} x+q_{i} y+r_{i}\right), i=1,2$

$\{$ pi, qi and ri\} is the consequent variables set, and they are computed using the least squares estimates method.

Layer 5: The addition of all the input signals from layer 4 is the output of this layer and is given by

$L_{i}^{5}=f=\sum_{i=1}^{2} \overline{w_{l}} f_{i}=\frac{\sum w_{i} f_{i}}{\sum w_{i}}$

The ANFIS optimization combines both the least square errors estimate (Jong Koo, 2008) and backpropagation algorithms (Roland, 2001), which establishes the output and input parameters, respectively, until the training is completed. The membership functions considered in this work are the Pi, triangular, trapezoidal, generalized bell, and Gaussian. These are chosen are they represent the most widely used MFs in various studies (Gupta S. , 2015); (Gupta, Verma, \& Mehlawat, 2011); (Ali, Ali, \& Sumait, 2015); (Zhao \& Bose, 2002); (Monicka, Sekhar, \& Kumar, 2011). Since the appropriate choice of the number and shape of membership functions is not very clear, even though these parameters determine the cost of training and computational complexity of the network (Talpur, MohdSalleh, \& Hussain, 2017), for each of the MF types, we varied the number from 2 to 10 . Furthermore, the effect of data size was investigated, and this was achieved by randomly portioning the data points for each of the routes. For each route, there were 500 data points, and this was segmented into $10 \%, 20 \%$, and $30 \%$ in that order representing 50, 100, and 150 sample points, respectively. For each sample path loss point, the ANFIS model was tested, and the performance was evaluated in terms of the RMSE.

The prediction of the path loss using the ANFIS model is bounded by the following constraints:

Root Mean Square Error (RMSE) $=0 \mathrm{~dB}$

Type of membership function $=$ Least RMSE dependent

$0 \leq$ number of epochs $\leq 1000$

$2 \leq$ number of membership functions $\leq 10$

\section{RESULTS AND DISCUSSION}

This section presents the results to show the effects that MF and data density have on the performance of ANFIS model in the prediction of path losses in both VHF and UHF bands.

\section{A. Broadcasting Band}

Figures 3-5 show the effects of membership functions and the number of epochs on the training for the three VHF transmitters along route 1. All the transmitters (i.e., NTA, Harmony, and Unilorin) are located within Ilorin, Kwara State, Nigeria, and they all operate within the VHF bands. 


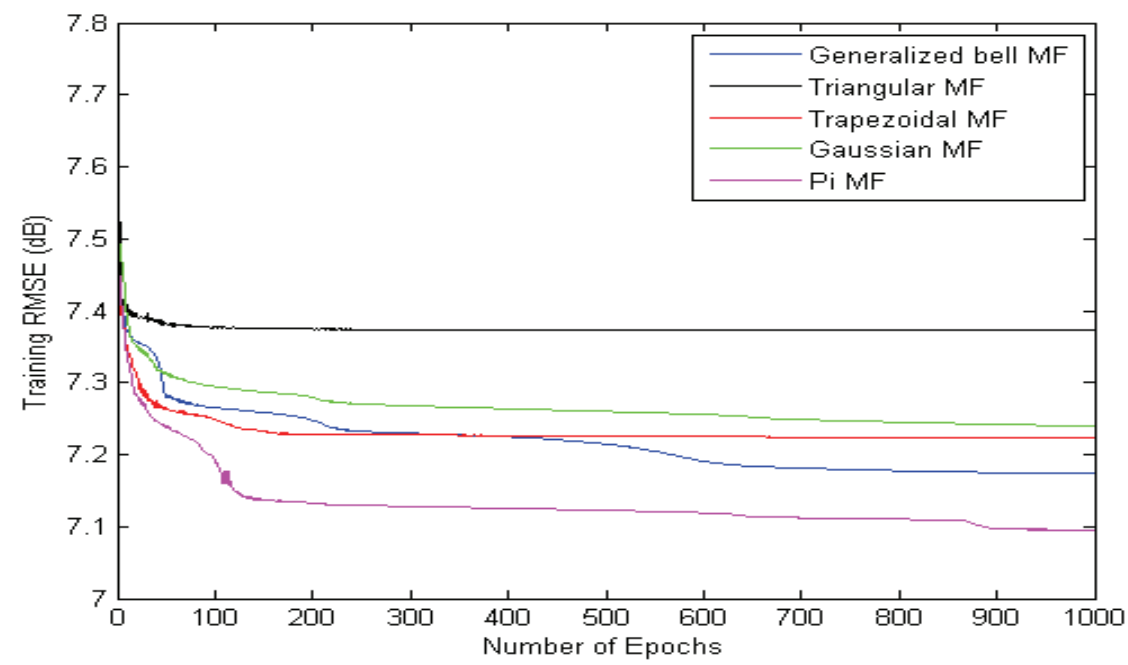

Figure 3. Effects of membership functions and the number of epochs on the training RMSE of NTA Ilorin transmitter.

Figure 3 depicts the RMSE and the number of epochs for NTA transmitter. The pi MF was found to produce the optimal RMSE for this route. This figure also reveals how the increase in the number of epochs reduced the RMSE. The $7.1 \mathrm{~dB}$ is consistent from about 150 epochs. Similarly, in Figure 4, the result for Harmony FM transmitter is presented, where the pi MF outperformed other types of MFs. The $5.87 \mathrm{~dB}$ of RMSE is the same from about 200 epochs. It is also observed that the pi MF is at much lower RMSE value in this transmitter when compared to NTA Ilorin transmitter, which is a TV station. In Figure 5, the pi membership function was also optimal for UNILORIN FM transmitter. The RMSE of $5.71 \mathrm{~dB}$ was obtained for 250 epochs. It is equally observed that the pi MF is at a value of RMSE of $5.71 \mathrm{~dB}$ for the UNILORIN transmitter, which is not too far from RMSE of between 5.85 and 5.9 $\mathrm{dB}$ for the Harmony transmitter.

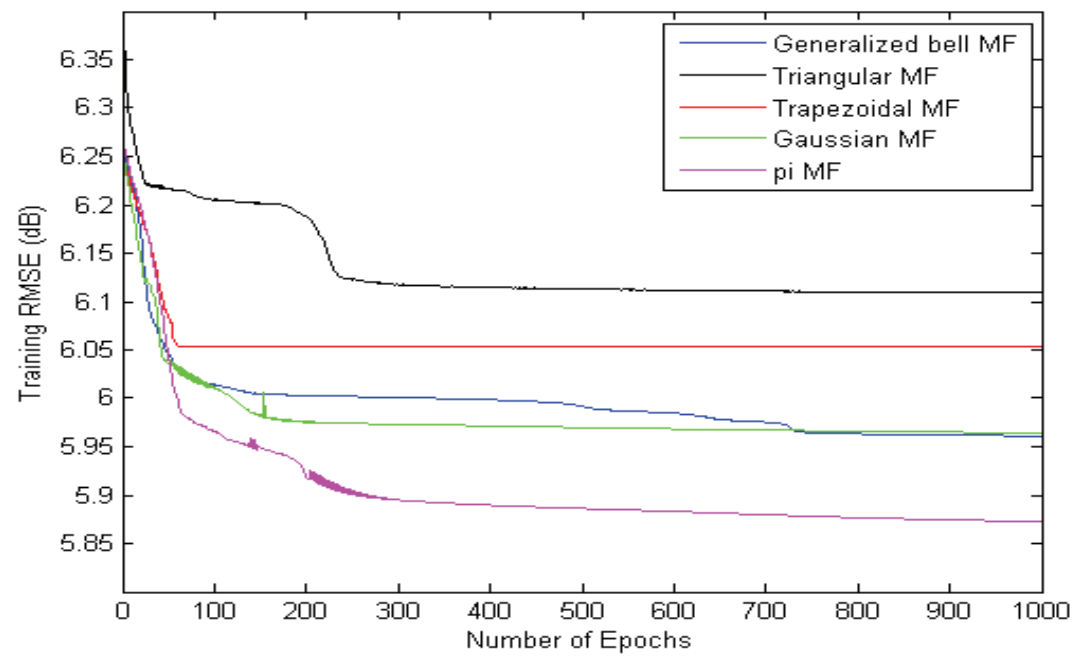

Figure 4. Effects of membership functions and the number of epochs on the training RMSE of Harmony FM transmitter in Ilorin. 


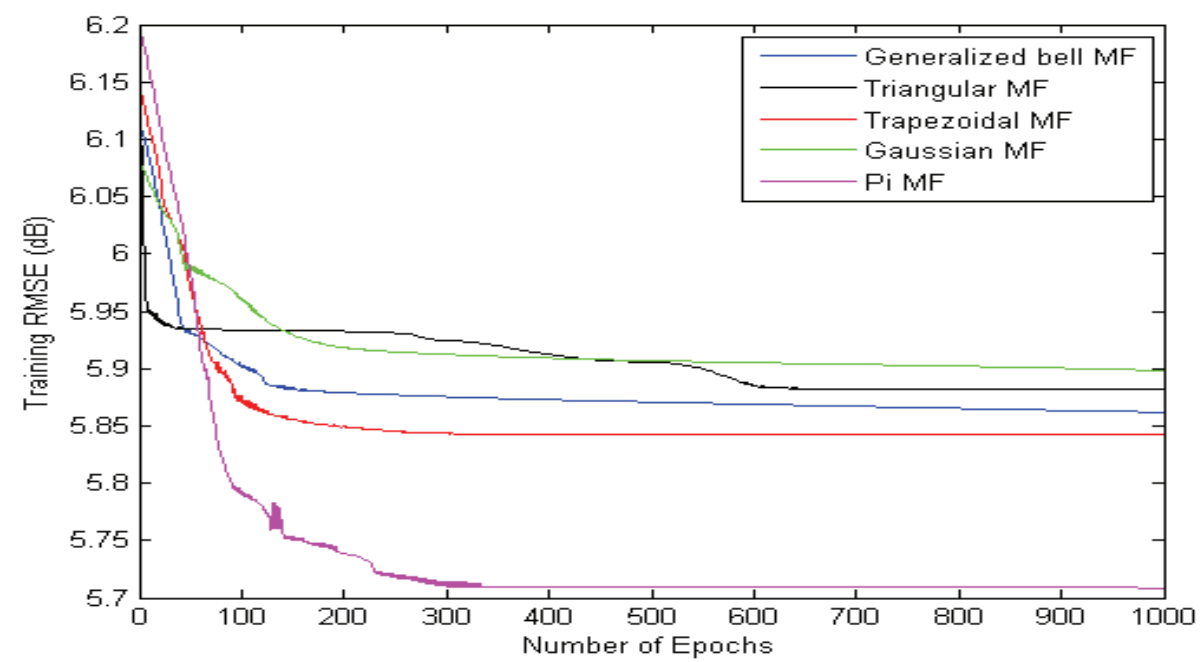

Figure 5. Effects of membership functions and the number of epochs on the training RMSE for UNILORIN FM transmitter.

Figures 6-9 present the results for the UHF bands (i.e., NDTV Obokun, NTA Ile-Ife, NTA Oshogbo and OSBC Oshogbo) all along route 1 . The transmitters are located within Osun State.

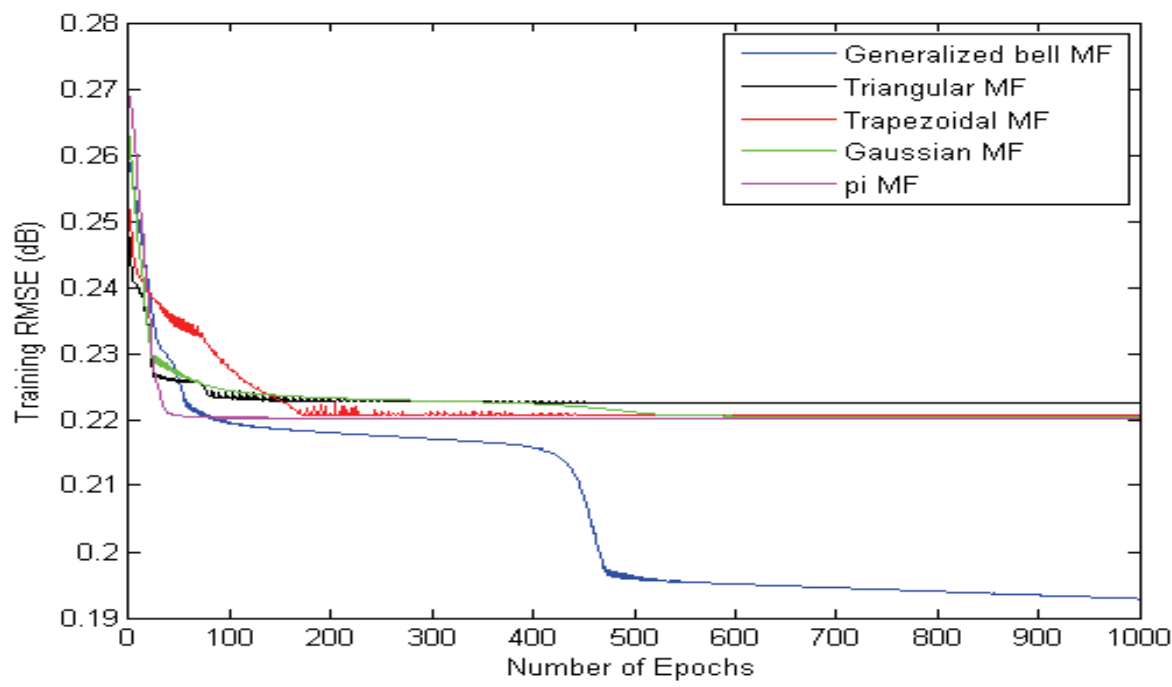

Figure 6. Effects of membership functions and the number of epochs on the training RMSE for NDTV, Obokun.

The training RMSE in dB versus the number of epochs for NDTV Obokun in Osun State is shown in Figure 6. It is observed that the generalized MF produced the superior RMSE value of about $0.19 \mathrm{~dB}$ and is same from about 480 epochs, even though the RMSE was $0.22 \mathrm{~dB}$ from about 80 epochs to over 400 epochs, while the next contending MF was pi. In Figure 7, the pi MF gave the lowest RMSE of about $0.48 \mathrm{~dB}$ in comparison to the others for NTA Ile- 
Ife in Osun State. The RMSE is also very low like NTA Obokun, but all the MFs have almost the same RMSE except for triangular MF. It is equally observed that the one with the best performance is not the same as was obtained for the NDTV Obokun. In Figures 9 and 10, the generalized bell has the best performance.

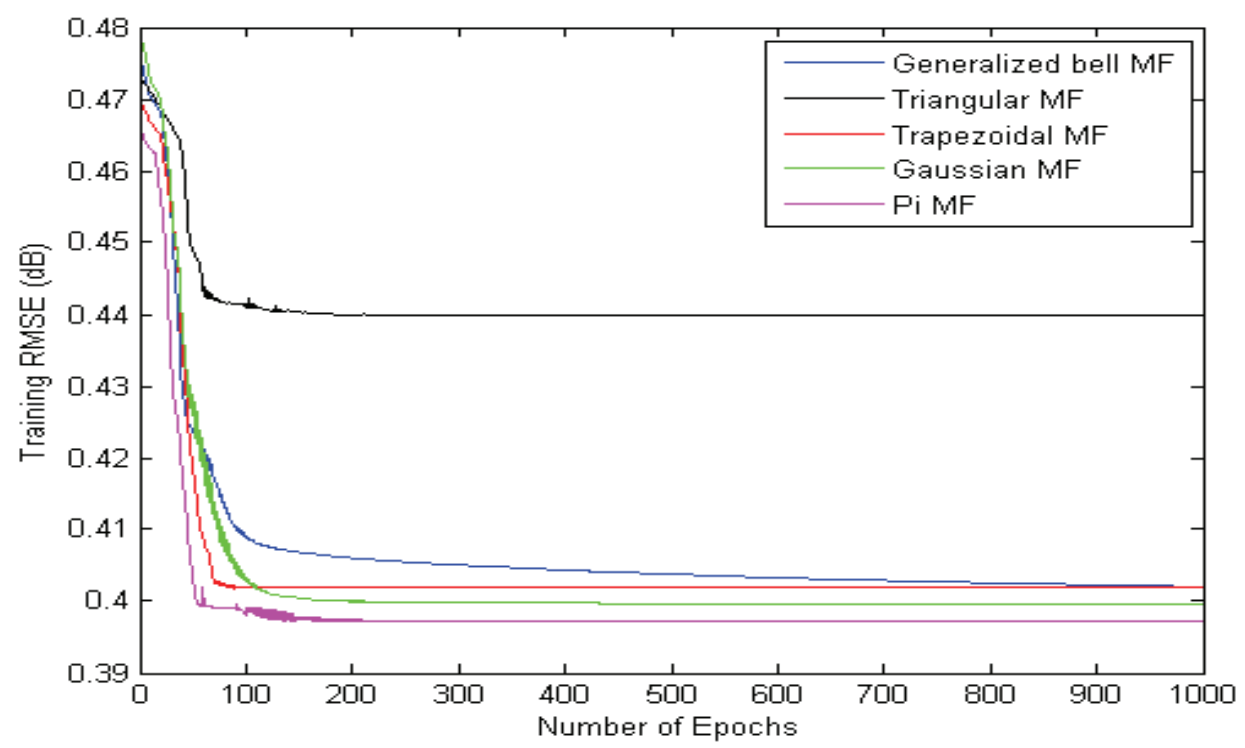

Figure 7. Effects of membership functions and the number of epochs on the training RMSE for NTA Ile-Ife, Osun State.

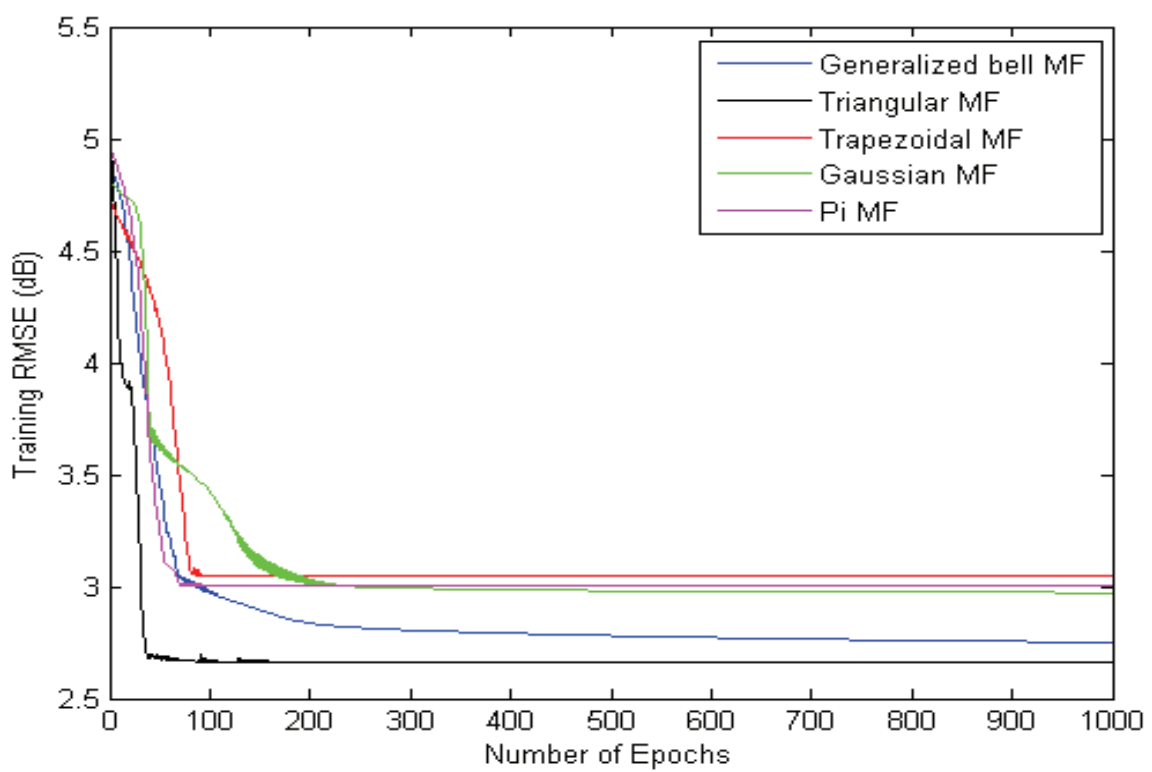

Figure 8. Effects of membership functions and the number of epochs on the training RMSE for NTA Oshogbo transmitter, Osun State. 


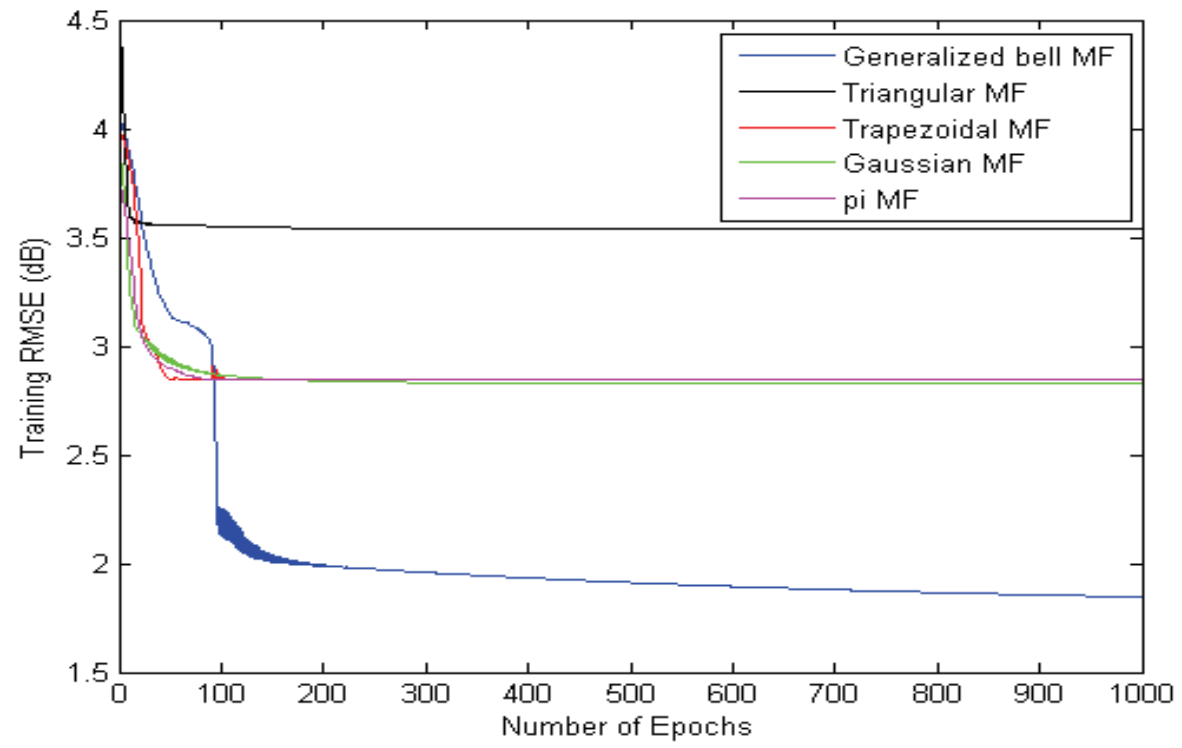

Figure. 9. Effects of membership functions and the number of epochs on the training RMSE for OSBC transmitter, Oshogbo, Osun State.

\section{B. Cellular Bands}

The results from the base transceiver station in Kano, Kano State, Nigeria, are presented for BTS1 only.

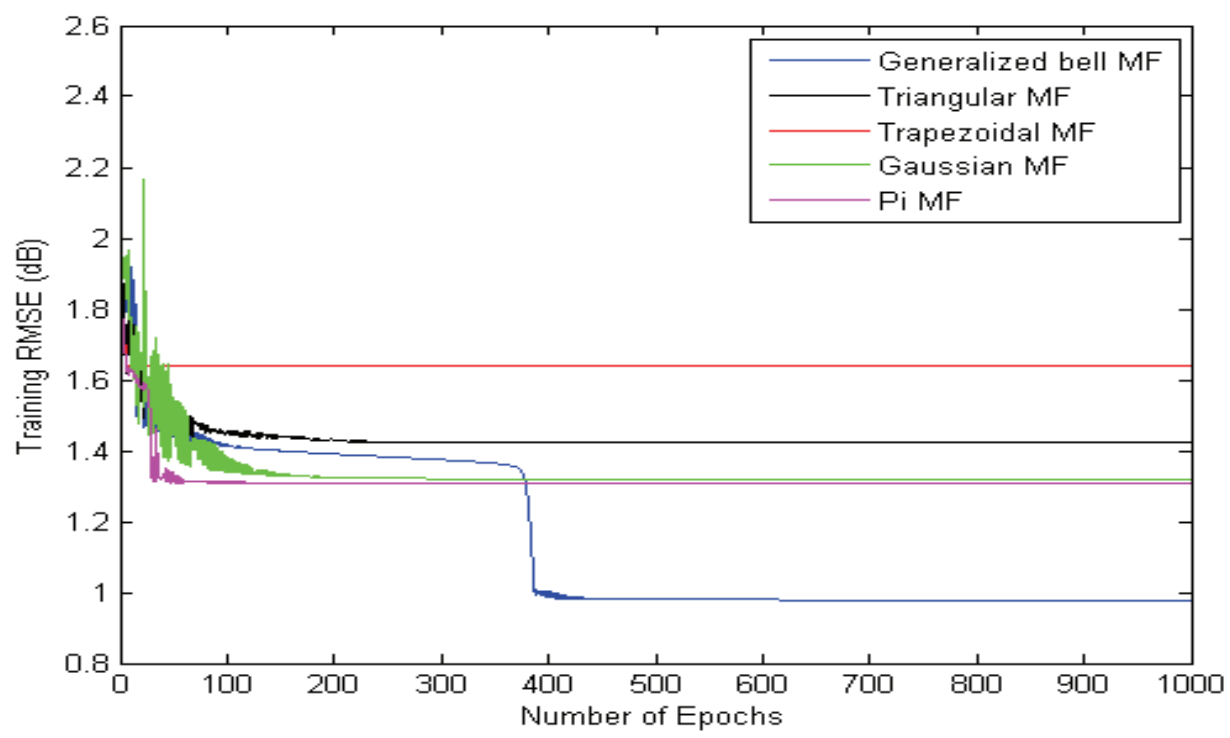

Figure. 10. Effects of membership functions and the number of epochs on the training RMSE for GSM BTS 1, Kano State. 
Figure 10 shows the effects of membership functions and the number of epochs on the training RMSE for GSM BTS 1, Kano State. In the case, up to 390 epochs, the pi MF gives the best RMSE and, thereafter, above 400 epochs, where the generalized bell outperformed the pi MF. The trapezoidal MF is of the highest RMSE of about $1.65 \mathrm{~dB}$, while the other three MFs have RMSE ranging between 1.35 and $1.42 \mathrm{~dB}$. The RMSE was $1.4 \mathrm{~dB}$ from the number of epochs of about 20 to 400 , after which it reduced to less than $1 \mathrm{~dB}$.

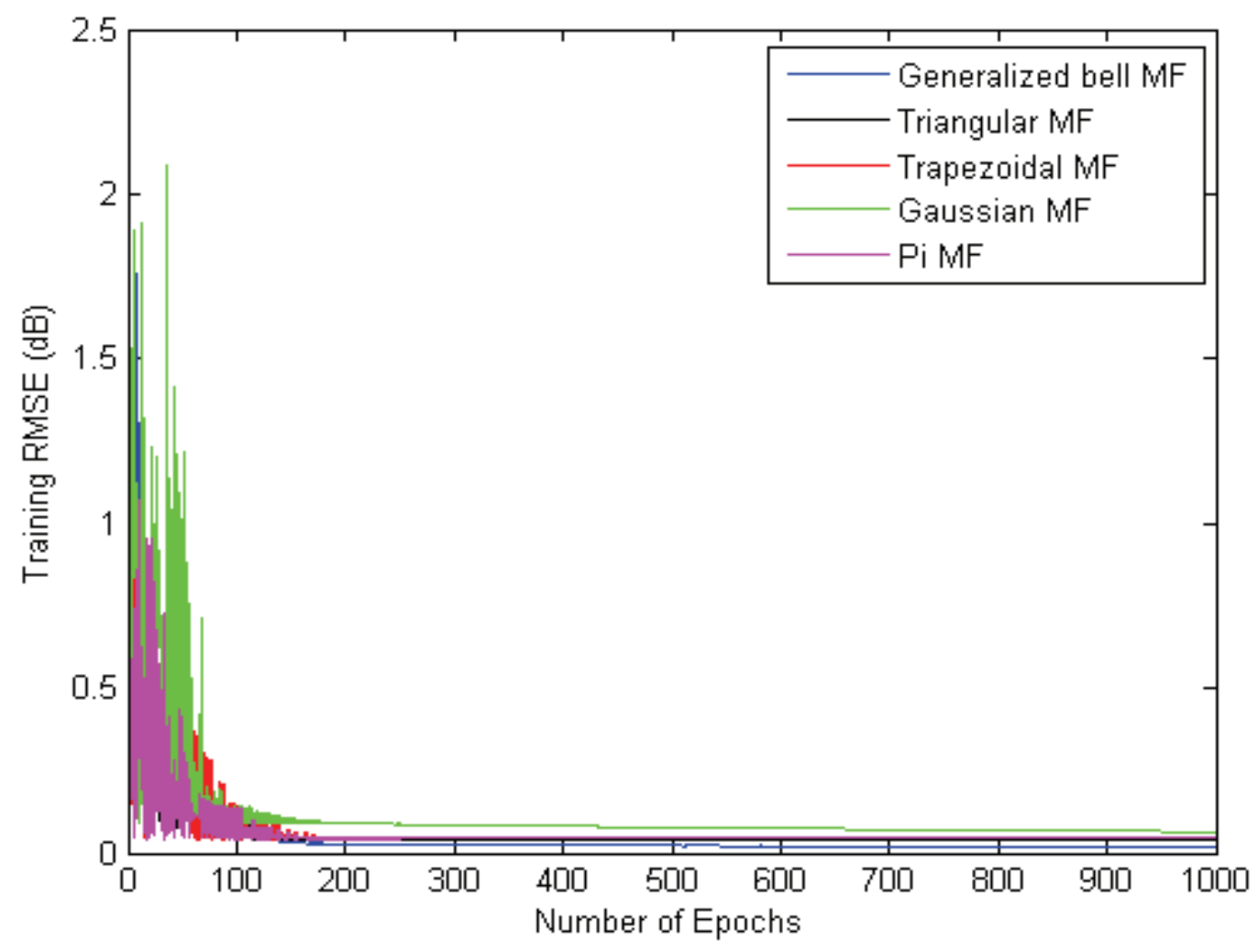

Figure 11. Effects of membership functions and the number of epochs on the training RMSE for Node B1 in Abuja.

The training RMSE in $\mathrm{dB}$ versus the number of epochs for Node B1 (Abuja in the Federal Capital Territory, Nigeria) as a representative of other ones considered is presented in Figure 11. The graph shows that the generalized bell MF is also optimal for the test Node B1 for WCDMA in Abuja, at RMSE of almost $0 \mathrm{~dB}$, even though all other MFs also have RMSEs ranging between 0.05 and $0.1 \mathrm{~dB}$. It is equally observed that the other MFs have values that are very low from number of epochs of 100 to 1000 . In tables 5 and 6, we provided a statistical summary of the RMSE for each MF across all the routes for the broadcasting systems and BTS/NodeBs for the cellular systems, respectively. 
Table 5. Route Specific Statistics for the RMSE for Broadcasting Transmitters.

\begin{tabular}{|l|c|c|c|c|c|}
\hline & Pi & Triangular & Trapezoidal & Generalized bell & Gaussian \\
\hline UNILORIN Tx_R1 & 5.23 & 5.17 & 5.295 & 5.128 & 5.315 \\
\hline UNILORIN Tx_R2 & 4.14 & 4.19 & 4.18 & 4.16 & 4.15 \\
\hline UNILORIN Tx_R3 & 4.48 & 4.65 & 4.71 & 4.61 & 4.54 \\
\hline HARMONY Tx_R1 & 5.91 & 6.13 & 6.05 & 5.99 & 5.98 \\
\hline HARMONY Tx_R2 & 5.54 & 5.56 & 5.53 & 5.55 & 5.52 \\
\hline HARMONY Tx_R3 & 6.13 & 6.32 & 6.18 & 6.22 & 6.24 \\
\hline NDTV Tx_R1 & 0.22 & 0.22 & 0.22 & 0.23 & 0.22 \\
\hline NDTV Tx_R2 & 0.5 & 0.48 & 0.54 & 0.45 & 0.48 \\
\hline NDTV Tx_R3 & 0.42 & 0.41 & 0.42 & 0.41 & 0.41 \\
\hline NTA ILE IFE Tx_R1 & 0.39 & 0.44 & 0.43 & 0.4 & 0.4 \\
\hline NTA ILE IFE Tx_R2 & 3.09 & 3.58 & 3.17 & 3.11 & 3.09 \\
\hline NTA ILE IFE Tx_R3 & 1.03 & 1.04 & 1.04 & 1.1 & 1.05 \\
\hline NTA Osogbo Tx_R1 & 3.04 & 2.71 & 3.13 & 2.88 & 2.87 \\
\hline NTA Osogbo Tx_R2 & 0.83 & 1.15 & 0.83 & 0.76 & 0.86 \\
\hline NTA Osogbo Tx_R3 & 4.55 & 4.82 & 4.72 & 4.56 & 4.89 \\
\hline OSBC Tx_R1 & 2.85 & 3.45 & 2.86 & 2.05 & 2.85 \\
\hline OSBC Tx_R2 & 2.56 & 2.64 & 2.6 & 2.46 & 2.17 \\
\hline OSBC Tx_R3 & 5.2 & 5.34 & 5.05 & 4.09 & 4.75 \\
\hline Average & $\mathbf{3 . 1 1}$ & $\mathbf{3 . 2 3}$ & $\mathbf{3 . 1 6}$ & $\mathbf{3 . 0 0}$ & $\mathbf{3 . 0 9}$ \\
\hline
\end{tabular}

Table 6. Route Specific Statistics for the RMSE for Cellular Transmitters.

\begin{tabular}{|l|c|c|c|c|c|}
\hline & Pi & Triangular & Trapezoidal & Generalized bell & Gaussian \\
\hline BTS_1 & 1.32 & 1.44 & 1.64 & 1.15 & 1.34 \\
\hline BTS_2 & 1.74 & 2.08 & 2.36 & 2.18 & 2.32 \\
\hline BTS_3 & 2.04 & 1.93 & 2.14 & 1.89 & 1.91 \\
\hline BTS_4 & 0.16 & 0.19 & 0.18 & 0.02 & 0.21 \\
\hline BTS_5 & 0.89 & 0.45 & 0.51 & 2.72 & 1.07 \\
\hline NodeB_1 & 0.06 & 0.06 & 0.06 & 0.05 & 0.12 \\
\hline NodeB_2 & 0.87 & 0.62 & 1.43 & 0.51 & 0.57 \\
\hline NodeB_3 & 2.58 & 2.62 & 2.9 & 2.58 & 3.37 \\
\hline NodeB_4 & 0.97 & 0.88 & 0.9 & 0.72 & 0.68 \\
\hline NodeB_5 & 1.66 & 1.57 & 1.81 & 1.63 & 1.88 \\
\hline Average & $\mathbf{1 . 2 3}$ & $\mathbf{1 . 1 8}$ & $\mathbf{1 . 3 9}$ & $\mathbf{1 . 3 5}$ & $\mathbf{1 . 3 5}$ \\
\hline
\end{tabular}




\section{Effects of Number of MF and Data Density on RMSE}

Table 7 gives an insight into how the number of MFs affects the RMSE. It is evident for the randomly selected transmitters, routes, BTS, and node that an increase in the number of MFs yielded a better result of the RMSE; however, care must generally be taken in the selection of the numbers so as to avoid overfitting of the results.

Table 7. Effects of the number of membership functions on the RMSE for the generalized bell-shaped membership function.

\begin{tabular}{|c|c|c|c|c|c|c|}
\hline \multirow{2}{*}{$\begin{array}{c}\text { Number of } \\
\text { Membership } \\
\text { Functions }\end{array}$} & $\begin{array}{c}\text { NDTV } \\
\text { Ibokun } \\
\text { (R1) }\end{array}$ & $\begin{array}{c}\text { NTA Ile } \\
\text { Ife (R2) }\end{array}$ & $\begin{array}{c}\text { NTA } \\
\text { Osogbo } \\
\text { (R3) }\end{array}$ & $\begin{array}{c}\text { OSBC } \\
\text { Osogbo } \\
\text { (R4) }\end{array}$ & $\begin{array}{c}\text { GSM } \\
\text { (BTS 4) }\end{array}$ & $\begin{array}{c}\text { WCDMA } \\
\text { (Node B4) }\end{array}$ \\
\hline 2 & 0.4728 & 4.4345 & 6.2961 & 7.3950 & 2.2154 & 3.3670 \\
\hline 4 & 0.3168 & 4.2142 & 5.5034 & 6.7891 & 0.9058 & 2.1063 \\
\hline 6 & 0.2514 & 3.7147 & 4.9844 & 6.1441 & 0.2266 & 0.9849 \\
\hline 8 & 0.2258 & 3.2874 & 4.7511 & 6.0392 & 0.1922 & 0.8893 \\
\hline 10 & 0.1929 & 3.0116 & 4.4769 & 5.9780 & 0.0087 & 0.6663 \\
\hline
\end{tabular}

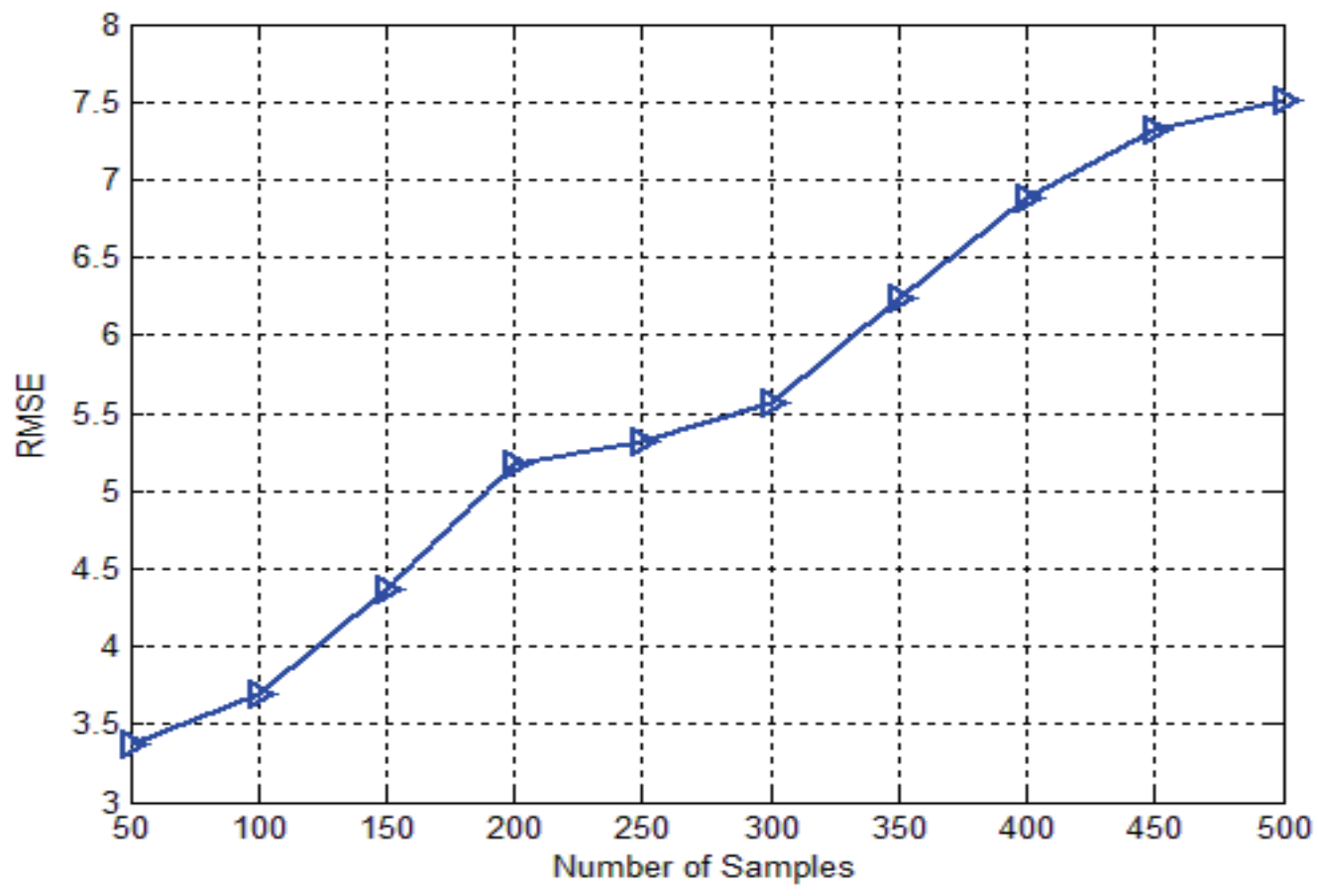

Figure 12. Effect of the number of training samples on RMSE for NTA Ilorin transmitter. 
Figure 12 also reveals that data density had significant impact on the ANFIS method. An increment in the number of data samples increased the RMSE, while a decrease in the data samples also decreased the RMSE. This is in contrast to the conventional heuristic method such as the ANN where large data increase the training and accuracy particularly in deep learning neural networks (Markham \& Terry R. Rakes, 1998) (Y. \& Y, 2011), even though findings from various literature have shown that the deep learning architectures such as the deep belief network, convolutional neural network, attentive deep neural network, stack autoencoder, generative adversarial network, deep reinforcement learning, deep long short term memory, and deep recurrent neural network have the potential of providing improved prediction accuracy especially when the amount of the data size is large (Adebowale, et al., 2021).

\section{Comparison with Other Methods}

In (Ojo, Imoize, \& Alienyi, 2020), measured data were used as input variables into two machine learning-based path loss prediction models that were developed. The radial basis function neural network (RBFNN) and the multilayer perception neural network (MLPNN) are the developed path loss prediction model, which were subsequently compared to the measured path loss, with RBFNN having lower values of root mean squared errors (RMSEs), and so they are concluded to be more accurate than the MLPNN. The RBFNN gave the most accurate results of the two machine learning-based path loss prediction models when they were compared with five existing empirical models.

Traditional channel models were compared to a channel model obtained using Deep Learning (DL) techniques utilizing satellite images aided by a simple path loss model. Experimental measurements were gathered and composed the training and test sets. The paper considered path loss modelling techniques offered by state-of-the-art stochastic models and a ray-tracing model for comparison and evaluation. The result showed an increase in the predictive performance of the satellite images, and also the model-aided technique offers an improvement. The proposed DL model was capable of improving path loss prediction at unseen locations (Thrane, Zibar, \& Christiansen, 2020).

Machine learning techniques, to alleviate the dilemma of channel complexity and time-consuming process that the measurements take, were used to demonstrate alternative procedures beyond traditional channel modeling so as to enhance the path loss models. The demonstrated regression used the measurement data of a certain scenario to successfully assist the prediction of path loss model of a different operating environment (Aldossari \& Chen, 2020)

In another research work by (Zhang, Wen, Yang, He, \& J., 2019), the machine-learning-based path loss prediction was presented by using measured data to evaluate the performance of different models such as artificial neural network, support vector regression, and random forest. It was shown that these machine-learningbased models outperform the log-distance model.

\section{CONCLUSIONS}

This paper investigates the impact of the membership function and data density on the performance of ANFISbased path loss model in predicting path losses in the VHF and UHF bands. Findings from the work show that, on route specific analysis, there is inconsistency in the MF performance across the bands. This is attributed to the nature of radio wave propagation in build-up environments. The complex nature of the interaction of the waves with obstacles along the propagation path makes it almost impossible to have a linear relationship between the dependent and independent variables. However, for the broadcasting bands, the generalized bell MF shows better performance with an average RMSE of $3.00 \mathrm{~dB}$ across all the routes, followed by Gaussian, Pi, trapezoidal, and triangular MF in that order, with average RMSE values of $3.09 \mathrm{~dB}, 3.11 \mathrm{~dB}, 3.16 \mathrm{~dB}$, and $3.23 \mathrm{~dB}$, respectively. For the cellular 
systems, triangular MF has the lowest average RMSE of $1.18 \mathrm{~dB}$ followed by Pi, generalized bell, Gaussian, and trapezoidal with average RMSE values of $1.23 \mathrm{~dB}, 1.35 \mathrm{~dB}, 1.35 \mathrm{~dB}$, and $1.39 \mathrm{~dB}$, respectively. This agrees with the existing comparative studies, where the triangular MF always outperformed other MFs.

However, for band specific models, the generalized bell MF had the best performance for WCDMA band, while triangular MF is most suited for GSM band. Furthermore, it can also be concluded that the higher the number of membership functions, the lower the RMSE, whereas it is a decrease in the data density that leads to a reduction in the RMSE values. This contrasts with ANN, where the data density improves the performance of the model.

The computational cost and efficiency of ANFIS based model rise as the number of inputs and training samples increases, even though it is well established from this paper that the increase in the number of data samples has not significantly yielded better RMSE; however, future research may focus on increasing the number of input attributes such as coordinates, frequency, and elevation parameters. Also, modifications in ANFIS layered architecture could be investigated. Other research spaces (i.e., shapes of the membership functions such as sigmoid) could also be investigated.

\section{REFERENCES}

Adebowale, Q. R., Faruk, N., Adewole, K. S., Abdulkarim, A., Olawoyin, L. A., Oloyede, A. A., ... Aliyu D. Usman \& Calafate, C. T. (2021). Application of Computational Intelligence Algorithms in Radio Propagation: A Systematic Review and Metadata Analysis. Mobile Information Systems, 1-20.

Aldossari, S., \& Chen, K.-C. (2020). Predicting the Path Loss of Wireless Channel Models Using Machine Learning Techniques in MmWave Urban Communications.

Ali, O. A., Ali, A. Y., \& Sumait, B. S. (2015). Comparison between the effects of different types of membership functions on fuzzy logic controller performance. International Journal, 76-83.

An investigation of membership functions on performance of ANFIS for solving classification problems, IOP. (2017). Conference Series. : Materials Science and Engineering.

Aymen, B. Z., \& Mohammed, A. (2012). A Multi-wall and Multi-frequency Indoor Path Loss Prediction Model Using Artificial Neural Networks. Computer Engineering and Computer Science Research Article.

Dalkilic, T. E., Hanci, B. Y., \& Apadydin, A. (2010). Fuzzy adaptive neural network approach to path loss prediction in urban areas at GSM-900 band, . Turk J Elec Eng \& Comp Sci, 1077-1094.

Dalkilic, T. E., Kula, K. S., \& Hanci, B. Y. (2014). Path Loss Prediction by Robust Regression Methods. International Journal of Computational Engineering Research (IJCER), 26-35.

DasMahapatra, R. (2015). Optimal Power Control for Cognitive Radio in Spectrum Distribution Using ANFIS. 2015 IEEE International Conference on Signal Processing Informatics, Communication and Energy Systems(SPICES) (s. 1-5). Kozhikode: IEEE.

Dela, C. J., \& Caluyo, F. S. (2013). Heuristic modelling of outdoor path loss for $9 \mathrm{~m}, 3 \mathrm{~m}$ and $1.5 \mathrm{~m}$ antenna at 677 MHz. IEEE Conference on Cybernetics and Intelligent Systems, (s. 117-122).

Di, W., Gang, Z., \& Bo, A. (2010). Application of Artificial Neural Networks for Path Loss Prediction in Railway Environment. 5th International ICST Conference on Communications and Networkingin China,. Beijing, China.

Eichie, O., Oyedum, D. A., \& A., M. A. (2017). Comparative Analysis of Basic Models and Artificial Neural Network Based Model for Path Loss Prediction. Progress in Electromagnetic Research M (PIER),, 133146. 
Erik, O., Hans-Jurgen, Z., \& Hajime, S. (2013). Macrocell Path-Loss Prediction Using Artificial Neural Network. IEEE Transactions on Vehicular Technology, 2735-2747.

Faruk, N., Adediran, Y., \& Ayeni, A. (2013). On the study of empirical path loss models for accurate prediction of TV signal for secondary users. Progress in Electromagnetic Research, 155-176.

Faruk, N., Jimoh, A., Bello, O., Obiyemi, O., Surajudeen-Bakinde, N., Oloyede, A., ... Ali, M. (2016). Clutter and Terrain Effects on Path Loss in VHF/UHF Bands . IET Microwaves, Antennas and Propagation, 1-29.

Faruk, N., Segun, I. P., Surajudeen-Bakinde, N. T., Oloyede, A. A., Abdulkarim, A., \& Lukman A. Olawoyin, M. A. (2019). Path Loss Predictions in the VHF and UHF Bands within Urban Environments Experimental Investigation of Empirical, Heuristics and Geospatial Models. IEEE Access, 77293-77307.

Faruk, N., Surajudeen-Bakinde, N. T., Oloyede, A. A., Popoola, S. I., Abdulkarim, A. O., \& Atayero, A. A. (2019). ANFIS Model for Path Loss Prediction in the GSM and WCDMA Bands in Urban Area. Journal of Electrical Engineering, ELEKTRIKA, 1-10.

Gupta, N., Sharma, G., \& Sharma, R. S. (2014). A comparative study of ANFIS membership function to predict ERP user satisfaction using ANN and MLRA. International Journal of Computer Applications.

Gupta, P., Verma, S., \& Mehlawat, M. K. (2011). A membership function approach for cost reliability tradeoff of COTS selection in fuzzy environment. International Journal of Reliability, Quality and Safety Engineering, , 573-595.

Gupta, S. (2015). Use of triangular membership function for prediction of compressive strength of concrete containing nanosilica. . Cogent Engineering,.

Hosseinzadeh, S. H., Curtis, K., \& Wixted, D. (2019). An Adaptive Neuro Fuzzy Propagation Model for LoRaWAN, . Appl. Syst. Innov, , 1-11.

Jimoh, A., Surajudeen-Bakinde, N. T., Faruk, N., Adeseko, A., Obiseye, O., \& Olayiwola, W. (2015). Performance Analysis of Empirical Path Loss Models in VHF and UHF bands. 6th International Conference on Information and Communication Systems (s. 194-199). ordan University of Science and Technology, Amman, Jordan: IEEE.

JongKoo, J. (2007). Fuzzy and Neural Network Models for Analyses of Piles. Department of Civil Engineering Raleigh North Carolina University.

Markham, I. S., \& Terry R. Rakes. (1998). The effect of sample size and variability of data on the comparative performance of artificial neural networks and regression, . Computers \& Operations Research, 251-263.

Monicka, J. G., Sekhar, N. G., \& Kumar, K. R. (2011). Performance evaluation of membership functions on fuzzy logic controlled ac voltage controller for speed control of induction motor drive. International Journal of Computer Applications, , 8-12.

Ojo, S., Imoize, A., \& Alienyi, D. (2020). Radial basis function neural network path loss prediction model for LTE networks in multitransmitter signal propagation environments. Int. J. Commun. Syst. John Wiley \& Sons Ltd.

Oloyede, A., Faruk, N., \& Bello, W. (2016). Variation of Clutter Height and its Impact on Path Loss in the VHF/UHF Bands. . Advances in Wireless and OpticalCommunications, (s. 129-132). Riga, Latvia.

Onidare, O., Faruk, N., Olayiwola, W., Muhammad, M., Sowande, O., \& Adeseko, A. (28-39). (2016). Practical Error Bounds for Empirical Models at VHF/UHF bands. Bayero Journal of Engineering and Technology, 2016. 
Ozdemir, A. M., K., A. M., \& Gulsen, M. (2014). Loss of FM Radio Station Using Artificial Nueral Network.,. Journal of Electromagnetic Analysis and Applications, 358-365.

Phaiboon, S., Phokharatkul, P., \& Kittithamavongs, P. (2006). Muti-Layer Fuzzy Logic Sets for Mobile Path Loss in Forests. Institute of Electrical and Electronics Engineers IEEE.

Phaiboon, S., Phokharatkul, P., \& Kittithamavongs, P. (2006). Muti-Layer Fuzzy Logic Sets for Mobile Path Loss in Forests. nstitute of Electrical and Electronics Engineers IEEE.

Popoola, S. I., Adetiba, E., Atayero, A. A., Matthews, V. O., N, F., \& Carlos, T. C. (2018). Optimal Path Loss Prediction Model for Rural Propagation Environments using Feed-Forward Neural Networks. Cogent Engineering, Cogent Engineering, Taylor and Francis, 1-19.

Popoola, S. I., Jefia, A., Atayero, A. A., Kingsley, O., \& Nasir Faruk, O. F. (2019). Determination of Neural Network Parameters for Path Loss Prediction in Very High Frequency Wireless Channel,. IEEE Access.

Popoola, S., Atayero, A., Faruk, N., Calafate, C., Adetiba, E., \& Matthews, V. (2017). "Calibrating the Standard Path Loss Model for Urban Environments using Field Measurements and Geospatial Data. The 2017 International Conference of Wireless Networks, (s. 513-518,). London.

Popoola, S., Faruk, N., Oloyede, A., Atayero, A., Surajudeen-Bakinde, N., \& L. Olawoyin. (2019). Characterization of Path Loss in the VHF Band using Neural Network Modeling Technique. 19th International Conference on Computational Science and Its Applications (ICCSA), (s. 166-171). Saint Petersburg, Russia.

Roland, S. (2001). Advanced Control Engineering (1st ed.). Oxford: Reed Educational and Professional Publishing Ltd.

Salman, M., Faruk, N., Surajudeen-Bakinde, N. T., Popoola, S., Oloyede, A., \& Olawoyin, L. (2018). On Adaptive Neuro Fuzzy Model for Path Loss Prediction in the VHF Band",. The ITU Journal: ICT Discoveries, Special issue 1, 1-9.

Sotirious, P. S., Sotirious, K., Konstantinos, A. G., Katherine, S., \& John, N. S. (2013). Optimal Artificial Neural Network Design for Propagation Path-Loss Prediction Using Adaptive Evolutionary Algorithm. 7th European Conference on Antennas and Propagation.

Sug, H. (tarih yok). The effect of training set size for the performance of neural networks of classification. WSEAS Trans Comput, , 1297-1306.

Supachai, P., Pisit, P., \& Suripon, S. (2006). Multi-layer Fuzzy Logic Sets for Mobile Path Loss in Forests. IEEE Region 10 Conference (s. 1-4). Hong Kong, China.: IEEE .

Surajudeen-Bakinde, N. T., Faruk, N., Salman, M. A., Popoola, S. I., Oloyede, A. A., \& Olawoyin, L. A. (2018). On Adaptive Neuro-Fuzzy Model For Path Loss Prediction In The Vhf Band. ITU Journal: ICT Discoveries, Special Issue, $1-9$.

Surajudeen-Bakinde, T., N., Faruk, N., Popoola, S. I., Salman, M. A., Oloyede, A. A., ... Calafate, C. T. (2018). Path Loss Predictions for Multi-Transmitter Radio Propagation in VHF Bands using Adaptive Neuro-Fuzzy Inference System. International Journal Engineering Science and Technology (JESTECH), Elsevier, 679-691.

Talpur, N., MohdSalleh, M., \& Hussain, K. (2017). An investigation of membership functions on performance of ANFIS for solving classification problems,. Conference Series . Materials Science and Engineering.

Tamma, A., Rabbie, A., \& Mustafa, K. (2015). Propagation Path Loss for Great Tripoli Area at 900, 1800, and $2100 \mathrm{MHz}$ frequency Neural Network Approach to Model the bands. International Conference on Sciences and Techniques of Automatic Control and Computer Engineering-STA, . Tunisia. 
Taskin, K. (2009). Increasing the accuracy of neural network classification using refined training data, . Environmental Modelling\& Software, 850-858.

Thrane, J., Zibar, D., \& Christiansen, H. L. (2020). Model-Aided Deep Learning Method for Path Loss Prediction in Mobile Communication Systems at 2.6 GHz. IEEE Access 8 .

Turkan, E., Berna, Y., \& Aysen, A. (2010). Fuzzy Adaptive Neural Network Approach to Path Loss Prediction in Urban Areas at GSM-900 band. Turk J ElecEng\& Comp Sci, 1077-1094.

V., G., \& C, S. S. (2009). Secure Path Loss Prediction in Fringe Areas Using Fuzzy Logic Approach. International Conference on Advances in Computing, Control, and Telecommunication Technologies (s. 372-375). IEEE.

Vishal, G., \& Sharma, S. (2009). Secure Path Loss Prediction in Fringe Areas Using Fuzzy Logic Approach. IEEE International Conference of Advances in Computing, Control and Telecommunication Technologie, (s. 372-375). Trivandrum, Kerala, India.

Y., Z., \& Y, W. (2011). Advances in Intelligent and Soft Computing,. Berlin, Heidelberg: Springer.

Zhang, Y., Wen, J., Yang, G., He, Z., \& J., W. (2019). Path Loss Prediction Based on Machine Learning Principle, Method, and Data Expansion. Applied Sciences.

Zhao, J., \& Bose, B. K. (2002). Evaluation of membership functions for fuzzy logic controlled induction motor drive. In IEEE 2002 28th Annual Conference of the Industrial Electronics Society (s. 229-234). IECON02.

Zhong, X., \& Zhou, Y. (2012). Maintaining Wireless Communication Coverage Among Multiple Robots Using Fuzzy Neural Network. International Conference on Mechatronic and Embedded Systems and Applications, , (s. 35-41.). Suzhou, China. . 